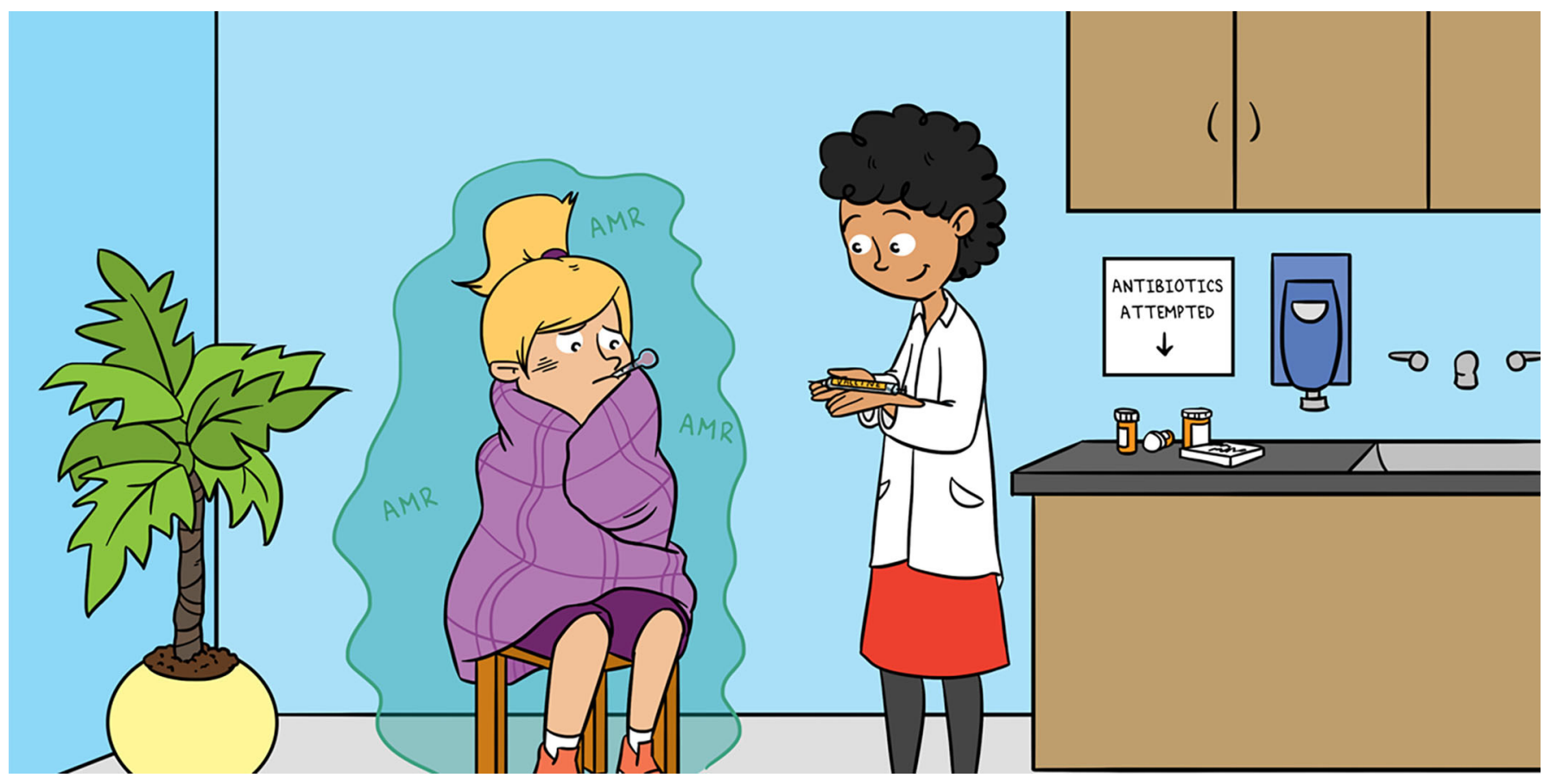

\title{
ANTIMICROBIAL RESISTANCE: A TALE OF NASTY ENEMIES AND POWERFUL WEAPONS
}

\author{
Fabiola Vacca ${ }^{1,2 t}$, Dario Cardamone ${ }^{1,3 t}$, Marco Troisi ${ }^{1,2 \dagger}$, Claudia Sala ${ }^{1 *}$ and Rino Rappuoli \\ ${ }^{1}$ Monoclonal Antibody Discovery Laboratory, Fondazione Toscana Life Sciences, Siena, Italy \\ ${ }^{2}$ Department of Biotechnology, Chemistry and Pharmacy, University of Siena, Siena, Italy \\ ${ }^{3}$ University of Turin, Turin, Italy
}

YOUNG REVIEWERS:

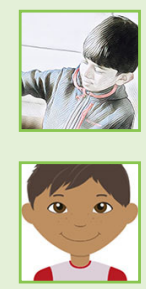

AARAV

AGE: 8

SINHA

AGE: 8
Have you ever had a sore throat, cough, or fever? All of us have felt badly at least once in our lives! A doctor may have helped you by prescribing antibiotics to kill the microbes responsible for the infection, thus eliminating pain, cough, and fever. Thanks to medicines like antibiotics, we can recover quickly from diseases. Unfortunately, the extraordinary power of antibiotics is threatened by a phenomenon called antimicrobial resistance. What is antimicrobial resistance and is there anything we can do to stop it? In this article, we describe antimicrobial resistance, how it may arise, and how we can help to prevent it by vaccination.

Let us clarify an important point before we get started: most microbes, especially bacteria, are our friends and live with and within us, for instance in our guts or on our skin. Though small, these microbes do an incredible job helping us digest food and protecting us from external 


\section{ANTIBIOTICS}

Drugs used to treat diseases caused by bacteria.

\section{ANTIMICROBIAL} RESISTANCE (AMR):

The ability of bacteria to survive treatment with antibiotics. AMR is due to bacterial genes that provide the bacteria with protection from the antibiotic. enemies that cause disease. However, there are some bad microbes that we should keep at bay because they are dangerous. Keep reading to see how we can fight and defeat them.

\section{IS IT POSSIBLE FOR AN ANTIBIOTIC TO BECOME USELESS?}

In many cases, we fall sick because invisible living microbes have invaded our bodies, causing an infection that makes us feel sick. Fortunately, there are medicines, called antibiotics, to help us get better. The word "antibiotic" comes from Greek and means "opposing life." This explains what antibiotics do: they kill our enemies, the bad bacteria. Antibiotics can be produced by friendly bacteria, by molds or plants, or they can be synthetic molecules produced in laboratories. Antibiotics interfere with processes essential for bacterial life. For example penicillin, discovered by Alexander Fleming in 1928, is produced by the mold Penicillium notatum and blocks bacterial multiplication by preventing the outer wall of the bacterial cell from developing. Without the cell wall, bacteria burst and die. Many antibiotics have been discovered since penicillin, and all of them are powerful weapons against invading microbes. In addition, thanks to the progress of science, it is now possible to mass-produce synthetic antibiotics and use them to successfully treat bacterial infections.

It may seem that, once discovered, antibiotics should remain effective against bacteria forever. Unfortunately, this is not the case. Bacteria are smart and they try to survive in the presence of antibiotics by becoming resistant to these drugs, meaning the antibiotics cannot harm them anymore. This bacterial ability is known as anti-microbial resistance (AMR). Because of AMR, even the most potent antibiotic can become useless in a short period of time [1].

\section{HOW DO BACTERIA ACQUIRE RESISTANCE TO ANTIBIOTICS?}

To test whether an antibiotic is useful against a certain type of bacterium, scientists can put bacteria in contact with the antibiotic and check whether the bacteria die (sensitive bacteria) or survive (resistant bacteria). This is a direct measurement of the potency of the antibiotic and the sensitivity of the bacteria to the drug. Alternatively, we can read the bacterium's "blueprint," which is called the genome or the DNA. The DNA contains the information that regulates the life of the bacterium and provides the instructions to make proteins, which are the building blocks of most organisms. In the case of bacteria, we can find and read the particular portions of their genomes that explain how they became resistant to an antibiotic. 
Figure 1

How antimicrobial resistant (AMR) bacteria arise and spread. (A) Bacteria that cause an infection in the body, for instance in the gut, are mostly

antibiotic-sensitive (blue). One of them may develop AMR (red) because of a mutation in its DNA. (B)

Antibiotics, here shown as pills, cure the

infection and kill almost all of the blue bacteria, but the red ones survive and multiply, until they reach a very high number (see panel C). This is dangerous because

antibiotic-resistant bacteria are difficult to kill and can cause a severe infection to the body. (D) The red bacterium can then transfer a piece of DNA to a sensitive bacterium (the blue one), transforming it into a resistant bacterium also.

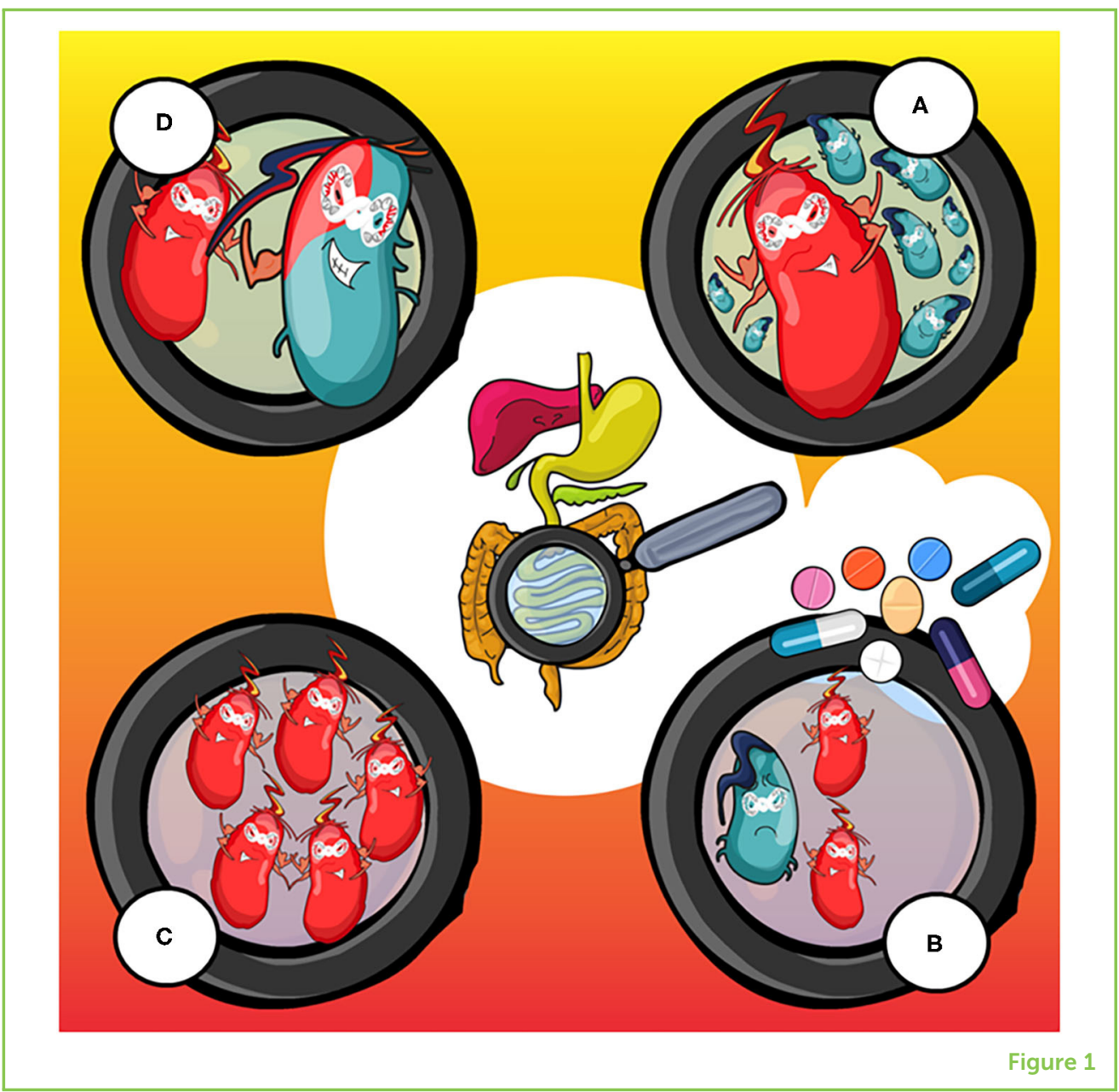

The bacterium's "blueprint" undergoes changes, known as mutations, that sometimes help a bacterium to survive in the presence of antibiotics. So, bacteria that are sensitive to antibiotics today could develop AMR tomorrow through mutations in their genomes. Bacteria can also transfer portions of their DNA to other bacteria, so they can basically "learn" from the bacteria that are already antibiotic resistant (Figure 1).

What happens if we use antibiotics too frequently? We put so much pressure on bacteria to survive that they become increasingly resistant. In other words, AMR bacteria will spread more and more and throughout the human population [2]. By limiting the use of antibiotics as much as possible, we reduce this pressure. This is why we need alternatives to antibiotics, and ways to reduce our risk of developing diseases that need to be treated with these drugs.

\section{OUR ARMY: THE IMMUNE SYSTEM}

The human immune system is composed of cells and molecules that specifically protect us against external invaders, such as bacteria and 


\section{ANTIGENS}

Proteins or sugars from a microbe that are recognized as foreign by the immune system. Antigens can be included in vaccines to teach the immune system what the microbe is made of

\section{ANTIBODIES}

Substances produced by the immune system that help in the fight against our enemies, the bacteria and the viruses.

IMMUNOLOGICAL MEMORY

The ability of the immune system to rapidly and specifically recognize a microbe that it has already encountered. It is the basis of vaccination.

viruses. When the body is infected with a bacteria or virus, that microbe is recognized by the immune system as "foreign," because it is usually not present in the body. The parts of the infecting organism that the immune system "sees" are called antigens, and these antigens are usually present on the surface of the bacteria or virus. To block antigens, the immune system produces substances called antibodies. Antibodies bind to the antigens, acting like specific arrows capable of recognizing the microbes and killing them.

During this battle between the immune system and microbes, our immune cells memorize the features of the microbes they fight against, thus making it harder for the same type of microbe to invade the body again. So, if the same type of microbe ever thinks of coming back, it would be knocked out with no second thoughts. This is called immunological memory and it is the basis of how vaccines work.

\section{THE VACCINE: TRAINING THE IMMUNE SYSTEM}

Now that you have an idea of how the immune system works, it will be easier to understand how important vaccines are for all of us, and how they help to prevent AMR. Vaccines are composed of dead, or sometimes weakened, microbes, which can cause no harm to us. Vaccines can also be made of bacterial antigens, such as proteins and sugars. When a vaccine is injected into the body, the dead or weakened microbe (or its parts) is seen as foreign by the immune system, in much the same way that an infectious microbe would be. The antigens contained in the vaccine stimulate the immune system to produce antibodies against them. Antibodies are highly specific and effective, but need some time to develop, which is why vaccines must generally be administered early in life [3]. Antibodies will hang around in the body, so that if the vaccinated person encounters the actual nasty microbe later, the antibodies will already be there to fight it.

Vaccination also allows the immune system to develop immunological memory, so that the body will respond quickly when it sees the microbe again. This is exactly what a vaccine is made to do: it teaches the immune cells what a bacterium or virus is made of, so that the immune system can prepare its weapons in advance and be ready when the real microbe comes (Figure 2). In the case of a bacterial infection, if the immune system of a vaccinated person is ready to tackle the bacteria, that person might not need external help from antibiotics.

\section{WHAT ARE THE DIFFERENCES BETWEEN ANTIBIOTICS AND VACCINES?}

So, you can see that antibiotics and vaccines are both used to fight microbes. But it is important to understand that they work in different 
Figure 2

Vaccines and the immune system. (A) The vaccine (syringe) teaches cells of the immune system what a certain type of bacteria is made of. (B) Immunological memory keeps a record of the bacterium, so that the body is ready to fight again if the same type of bacterium comes back. (C) When the body later encounters the actual bacterium, the trained immune cells can quickly produce antibodies (Y-shaped arrows) to fight the bacterial invaders, which try to defend themselves from the attack.

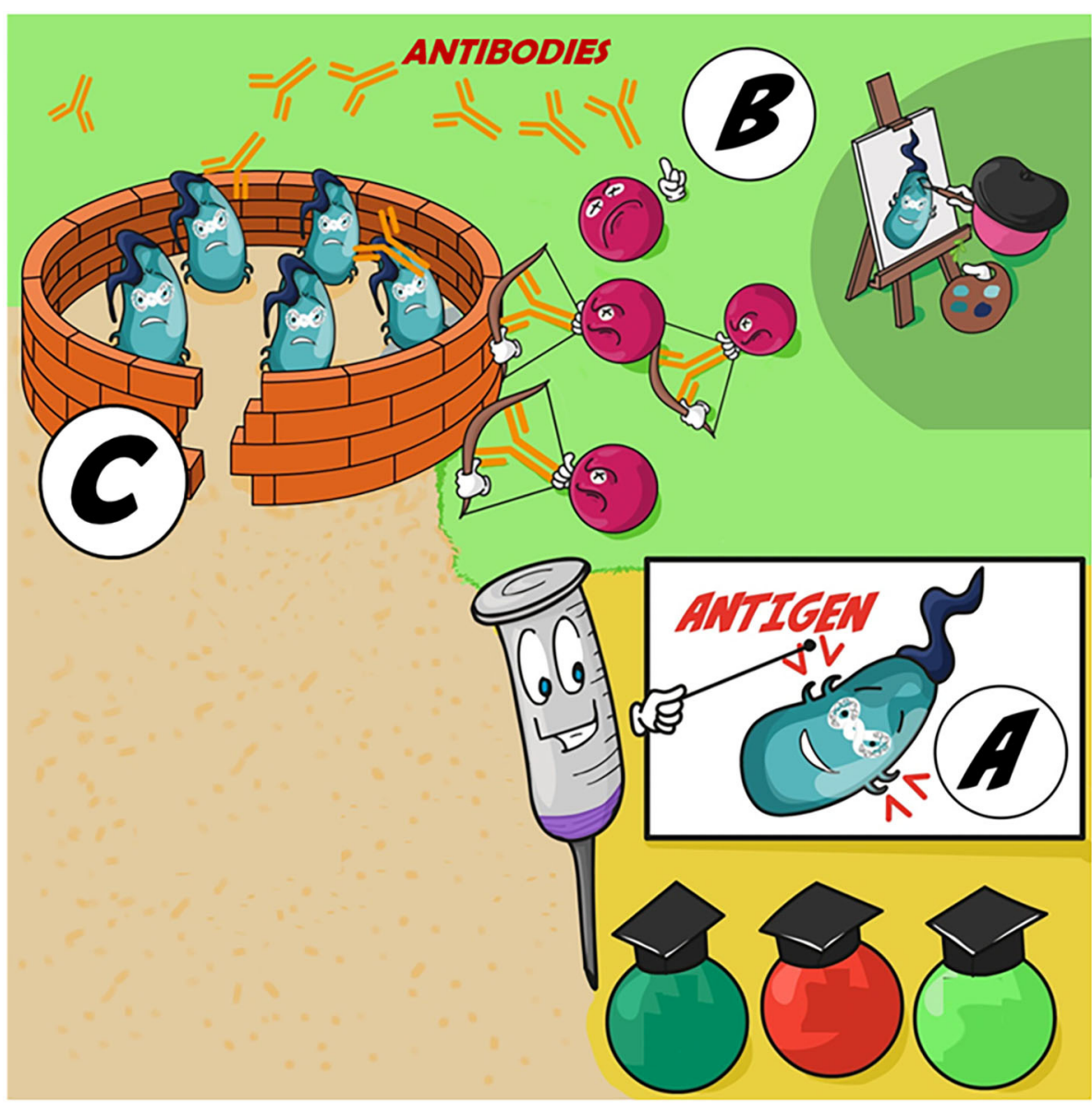

Figure 2

ways. First, while antibiotics are used to treat diseases that are already happening, vaccines are administered before we get infected, as a means of prevention. As you just learned, the role of vaccines is to guide the immune system to fight future infections. Second, antibiotics usually have one single mode of action, meaning that they attack bacteria in a specific way. In contrast, vaccines can expose our immune system to multiple bacterial antigens that are usually found on the bacterial surface. This exposure helps the immune system to attack the bacteria using multiple strategies at once. Last, vaccines can provide life-long protection from infections, which means that, if you are vaccinated against a specific type of bacteria, you will never be infected by them during your entire life. Antibiotics cannot do this.

\section{HOW CAN VACCINES DEFEND US AGAINST AMR?}

Reducing misuse of antibiotics is key for fighting AMR, and vaccines can help us reach this goal. Since vaccination prevents infections, it reduces the need for antibiotics. Less antibiotic use means less chance that bacteria will develop nasty antibiotic resistance. 
Figure 3

The importance of vaccination for herd immunity. In the top panel, there are very few vaccinated people (those with a bandage on their arms). There are not enough vaccinated people to protect the ones with the green and yellow shirts, who have not been vaccinated, from catching the virus from someone who is infected (the guy surrounded by red circles). In the bottom panel, there are enough vaccinated people to basically create a shield against the infection for people who, for medical reasons, cannot be vaccinated. This is herd immunity: after enough people are vaccinated, an infection cannot easily spread in the population, so all people, including those who are unvaccinated, are protected. Herd immunity helps with AMR because, if fewer people are infected, less antibiotics will need to be used

\section{HERD IMMUNITY}

Vaccinated people create a shield against the infection for people who, for medical reasons, cannot be vaccinated. In this way an infection cannot easily spread in the population, so all people, including those who are unvaccinated, are protected. Please see Figure 3.

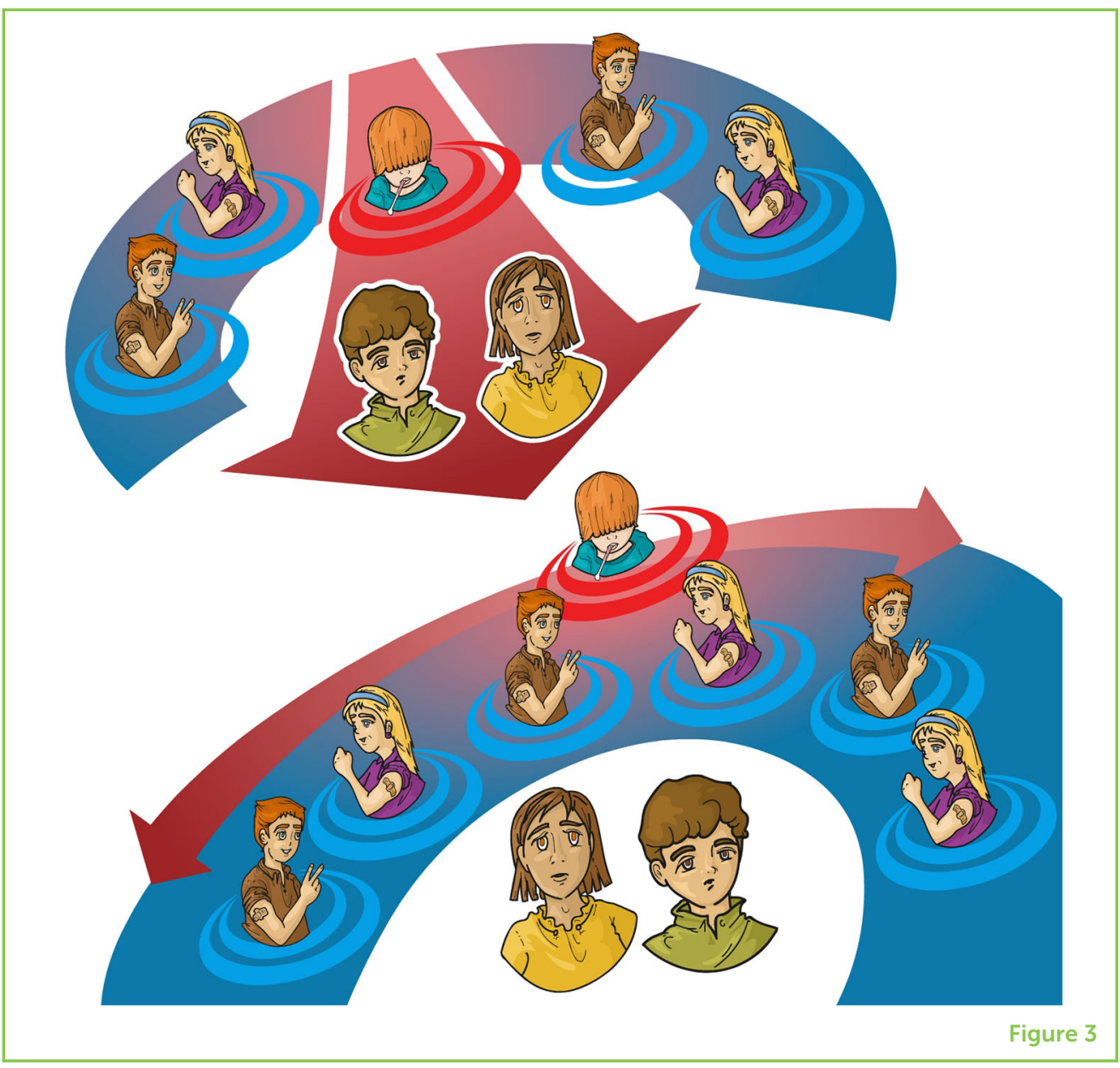

Today, vaccines are already helping us manage the problem of AMR. Let us look at influenza as an example. Influenza is the virus that causes "the flu." Although antibiotics are effective for stopping the multiplication of bacteria, they do not have any effect on viruses. However, influenza infection is often inappropriately treated with antibiotics. So, if people get vaccinated against influenza, we will reduce the number of influenza infections and therefore reduce the amount of antibiotics used inappropriately. We also reduce the pressure on bacteria to develop AMR. Other examples of how vaccines help to reduce AMR worldwide include bacterial diseases like diphtheria and pertussis, against which all of us were vaccinated as young children. Due to vaccination, these diseases are less frequent nowadays, which has greatly diminished the need for antibiotics to treat them. Again, this lowers the risk that the bacteria causing diphtheria and pertussis will develop AMR.

Finally, there is another important aspect of vaccination that you may have heard about, called herd immunity (Figure 3). Herd immunity is an indirect form of protection that is generally achievable only by vaccination. Basically, the more people that are vaccinated, the harder it is for microbes to spread in the population, because there are so few people left to infect. Herd immunity is crucial for protecting people 
who cannot be vaccinated, like infants, who are too young, and those who are too ill to receive vaccines $[4,5]$. The sum of all these effects of vaccines makes them an important line of defense against microbes and an effective weapon in combatting AMR.

Overall, we hope that this article has helped you understand what AMR is and why it is important that we use antibiotics according to the doctor's recommendations. Also, you should now know what a vaccine is and why it helps in our fight against AMR microbes.

\section{REFERENCES}

1. Bloom, D. E., Black, S., Salisbury, D., and Rappuoli, R. 2018. Antimicrobial resistance and the role of vaccines. Proc. Natl. Acad. Sci. U.S.A. 115:12868-71. doi: 10.1073/pnas.1717157115

2. Klemm, E. J., Wong, V. K., and Dougan, G. 2018. Emergence of dominant multidrug-resistant bacterial clades: lessons from history and whole-genome sequencing. Proc. Natl. Acad. Sci. U.S.A. 115:12872-7. doi: 10.1073/pnas. 1717162115

3. Clem, A. S. 2011. Fundamentals of vaccine immunology. J. Glob. Infect. Dis. 3:73. doi: 10.4103/0974-777X.77299

4. Jansen, K. U., and Anderson, A. S. 2018. The role of vaccines in fighting antimicrobial resistance (AMR). Hum. Vaccin Immunother. 14:2142-9. doi: 10.1080/21645515.2018.1476814

5. Lipsitch, M., and Siber, G. R. 2016. How can vaccines contribute to solving the antimicrobial resistance problem? MBio 7:e00428-16. doi: 10.1128/ mBio. 00428-16

SUBMITTED: 22 April 2020; ACCEPTED: 16 October 2020; PUBLISHED ONLINE: 11 November 2020.

EDITED BY: Michel Goldman, Institute for Interdisciplinary Innovation in healthcare (I3h), Belgium

CITATION: Vacca F, Cardamone D, Troisi M, Sala C and Rappuoli R (2020) Antimicrobial Resistance: A Tale of Nasty Enemies and Powerful Weapons. Front. Young Minds 8:554493. doi: 10.3389/frym.2020.554493

CONFLICT OF INTEREST: RR is an employee of GSK Vaccines.

The remaining authors declare that the research was conducted in the absence of any commercial or financial relationships that could be construed as a potential conflict of interest.

COPYRIGHT (? 2020 Vacca, Cardamone, Troisi, Sala and Rappuoli. This is an open-access article distributed under the terms of the Creative Commons Attribution License (CC BY). The use, distribution or reproduction in other forums is permitted, provided the original author(s) and the copyright owner(s) are credited and that the original publication in this journal is cited, in accordance with accepted 

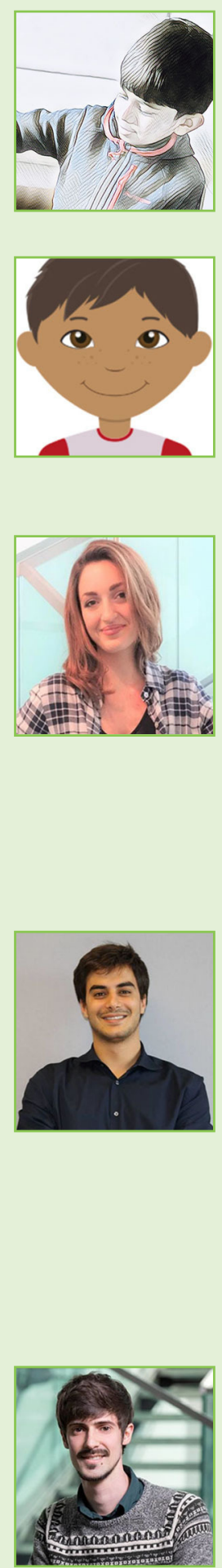

academic practice. No use, distribution or reproduction is permitted which does not comply with these terms.

\section{YOUNG REVIEWERS}

\section{AARAV, AGE: 8}

I am an eight-years-old in grade 3, who loves anything related to buildings and space. When I grow up, I want to be an architect. My favorite pastime is building things with Lego, Kapla, and Jenga. I love riding bike and playing with my friends. I also have lots of questions about everything, many that I have still not found answers for.

\section{SINHA, AGE: 8}

I like to play with friends, play video games, and science.

\section{AUTHORS}

\section{FABIOLA VACCA}

Fabiola Vacca is a Ph.D. student of the Biochemistry and Molecular Biology Doctoral Programme at the University of Siena. She works at TLS in the Monoclonal Antibody Discovery research group led by Dr. Rino Rappuoli. She earned a Master's degree in Medical Biotechnologies at the University of Siena. Through her Master's research, which focused on the development of a peptide as a new potential drug against antibiotic-resistant bacteria, she became interested in translational research and in drug resistance. Currently, she is working on setting up tools (genetically modified bacteria) that help understand how monoclonal antibodies work.

\section{DARIO CARDAMONE}

Dario Cardamone is a researcher in the Monoclonal Antibody Discovery laboratory led by Dr. Rino Rappuoli at TLS in Siena (Italy), and a Ph.D. fellow in Complex Systems for Life Science at the University of Turin. His research is focused on analyzing photos of bacteria obtained by potent microscopes in order to understand how antibodies kill the bacteria. He received his Master of Science in Mathematics from the University of Bologna. During his studies, he visited the Humboldt University of Berlin, working as a research assistant at the Zuse Institute Berlin (ZIB), an interdisciplinary research institute for applied mathematics and data-intensive high-performance computing.

\section{MARCO TROISI}

Marco Troisi is a Ph.D. student at the University of Siena and a member of the Monoclonal Antibody Discovery research group coordinated by Dr. Rino Rappuoli in TLS. His research project aims to develop new vaccines against bacteria resistant to antibiotics. Marco has a Bachelor's degree in Biology and a Master's degree in Medical Biotechnologies. His Master's research focused on the analysis of cancer cell signaling involved in cellular migration. During his studies, Marco became passionate about immunology and microbiology, with great interest in vaccinology. 


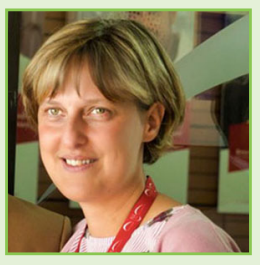

\section{CLAUDIA SALA}

Claudia Sala is a molecular microbiologist. She obtained her degree in Biological Sciences and her Ph.D. in Genetics and Molecular Biology at the University of Milan (Italy). She worked as a post-doctoral fellow in the laboratories of Prof. Stewart Cole, at the Pasteur Institute in Paris, and then at the Ecole Polytechnique Fédérale de Lausanne, where she was subsequently promoted to senior scientist. Her research was mainly focused on Mycobacterium tuberculosis. She moved to TLS in Siena in 2019 and joined the Monoclonal Antibody Discovery group led by Dr. Rino Rappuoli, where she performs research on monoclonal antibodies and vaccine development. ${ }^{*}$. sala@toscanalifesciences.org

\section{RINO RAPPUOLI}

Rino Rappuoli is head of the vAMRes laboratory at TLS in Siena and Chief Scientist and Head External R\&D at GSK Vaccines, Siena, Italy. He has received several awards including the Paul Ehrlich and Ludwig Darmstaedter Prize, the Gold Medal by the Italian President, the Albert B. Sabin Gold Medal, the Canada Gairdner International Award, and the European Inventor Award for Lifetime Achievement. He developed the pertussis and meningococcus $B$ vaccines, among others, and was nominated third most influential person worldwide in the field of vaccines. Dr. Rappuoli is among the world's scientific leaders dedicated to sustaining global health.

${ }^{\dagger}$ These authors have contributed equally to this work 